Universidade de Brasília

Faculdade de Economia, Administração, Contabilidade e Ciência da Inf. e Documentação

Departamento de Ciências Contábeis e Atuariais

Bacharelado em Ciências Contábeis

Nara Cristina Ferreira Mendes

ALTERAÇÕES NO ORÇAMENTO DO GDF:

análise dos créditos adicionais abertos no período 2005/2008

BRASÍLIA, 
Professor Doutor José Geraldo de Sousa Júnior Reitor da Universidade de Brasília

Professor Doutor Tomas de Aquino Guimarães

Diretor da Faculdade de Economia, Administração, Contabilidade e Ciência da Inf. e Documentação

Professor Mestre Elivânio Geraldo de Andrade Chefe do Departamento de Ciências Contábeis e Atuariais

Professor Mestre Wagner Rodrigues dos Santos Coordenador de Graduação do curso de Ciências Contábeis - diurno

Professor Mestre Alex Laquis Resende

Coordenador de Graduação do curso de Ciências Contábeis - noturno 
Nara Cristina Ferreira Mendes

ALTERAÇÕES NO ORÇAMENTO DO GDF:

análise dos créditos adicionais abertos no período 2005/2008

Trabalho de Conclusão de Curso (Artigo) apresentado ao Departamento de Ciências Contábeis e Atuariais da Faculdade de Economia, Administração, Contabilidade e Ciência da Informação e Documentação da Universidade de Brasília, como requisito à conclusão da disciplina Pesquisa em Ciências Contábeis e obtenção do grau de Bacharel em Ciências Contábeis.

Orientador: Prof. Mestre James Giacomoni.

BRASÍLIA, 
MENDES, Nara Cristina Ferreira.

Alterações no orçamento do GDF: análise dos créditos adicionais abertos no período 2005/2008. / Nara Cristina Ferreira Mendes - Brasília, 2009.

19 p.

Trabalho de Conclusão de curso (Artigo - Graduação) - Universidade de Brasília, 2009/2.

Bibliografia.

1. Créditos adicionais abertos 2. Orçamentário público 3. Governo do Distrito Federal. I. Faculdade de Economia, Administração, Contabilidade e Ciência da Informação e Documentação da UnB. II. Título. 
Nara Cristina Ferreira Mendes

ALTERAÇÕES NO ORÇAMENTO DO GDF: análise dos créditos adicionais abertos no período 2005/2008

Trabalho de conclusão de curso (Artigo) defendido no Departamento de Ciências Contábeis e Atuariais da Faculdade de Economia, Administração, Contabilidade e Ciência da Informação e Documentação da Universidade de Brasília como requisito à conclusão da disciplina Pesquisa em Ciências Contábeis e obtenção do grau de Bacharel em Ciências Contábeis e aprovado pela seguinte comissão examinadora:

Prof. Mestre. James Giacomoni

Orientador - Universidade Brasília (UnB)

Examinador - Universidade Brasília (UnB)

Brasília, $1^{\circ}$ de dezembro de 2009 
DEDICATÓRIA

A meus pais, Célio e Edna, que sempre estiveram ao meu lado, apoiando-me e incentivando meus estudos. 


\section{AGRADECIMENTOS}

A Deus por ter me possibilitado alcançar mais uma vitória;

Aos meus pais, os quais deram-me todo o apoio necessário;

Ao professor mestre James Giacomoni pelo acompanhamento e orientação durante a realização deste;

Aos profissionais da Secretaria de Fazenda, que se disponibilizaram a me ajudar. Sem essa colaboração, não seria possível a conclusão da pesquisa em tela; e

E aos meus familiares e amigos por estarem sempre ao meu lado. 
"Sabemos que todas as coisas cooperam para o bem daqueles que amam Deus.”

(ROMANOS 8.28) 


\title{
ALTERAÇÕES NO ORÇAMENTO DO GDF: análise dos créditos adicionais abertos no período 2005/2008
}

\begin{abstract}
RESUMO
Por meio de pesquisas bibliográfica e documental, este trabalho analisou o orçamento do Governo do Distrito Federal, identificando até que proporção o mesmo vem sendo flexível. Para tanto, levantou-se o montante de créditos adicionais abertos nos exercícios compreendidos entre 2005 a 2008, por órgão da administração e no total. Entre os resultados principais, observou-se alta proporção de créditos adicionais se comprados com os créditos autorizados na lei orçamentária. As Secretarias de Obras e de Educação foram as que mais se utilizaram desse mecanismo de retificação orçamentária. Em dois exercícios do período analisado, o montante de créditos adicionais abertos na Secretaria de Obras alcançou 83\% e $78 \%$ do total do valor autorizado inicialmente na lei orçamentária. Na Secretaria de Educação, em 2008 essa proporção foi de 73\%.
\end{abstract}

Palavras-chave: Governo do Distrito Federal; orçamento do GDF; lei orçamentária anual; créditos adicionais.

\section{INTRODUÇÃO}

A temática deste artigo são os créditos adicionais abertos pelo Governo do Distrito Federal (GDF) no período compreendido entre 2005 a 2008. Constituindo-se em instrumentos de retificação do orçamento em execução, os créditos adicionais garantem a necessária flexibilidade que deve existir em qualquer orçamento, mas, também, suscitam a questão da qualidade das previsões e estimativas quando da elaboração orçamentária.

A presente pesquisa foi estruturada visando colher dados quantitativos sobre os montantes de créditos adicionais abertos em cada um dos exercícios considerados. Não se ambicionou avaliar a natureza econômica ou programática das alterações realizadas por meio dos créditos adicionais. Esse enfoque, certamente muito interessante, poderá ser tema de outras investigações. Os montantes de créditos abertos permitem comparações com os valores do orçamento inicial, tanto em nível global, como de maneira segmentada por órgão do GDF, por exemplo. Na análise desses dados, certamente surge a questão da qualidade do planejamento. Ainda que dificilmente seja possível afirmações categóricas, a abertura de um grande volume de créditos adicionais ensejará interrogações sobre como as previsões e as estimativas são normalmente realizadas ou, resumindo, sobre a qualidade do planejamento.

A questão central a ser respondida pela pesquisa é o montante de créditos adicionais abertos no âmbito do orçamento do GDF, em cada um dos exercícios compreendidos no período 2005/2008, em cada uma de suas modalidades. Complementarmente, o trabalho levantará e analisará as fontes de recursos indicados como compensação para a abertura dos créditos adicionais, bem como, a incidência das alterações dos órgãos do GDF.

Enquanto no âmbito do orçamento federal são inúmeros os estudos e pesquisas sobre a execução orçamentária e financeira, não ocorre o mesmo sobre o orçamento do GDF. Assim, este estudo tem importância na medida em que supre essa carência de pesquisas aplicadas à 
gestão do GDF. Dá-se um pouco de visibilidade a esse assunto, aumentando a transparência das práticas de gestão pública, o que sempre necessário, já que o Poder Público executa suas ações com recursos retirados da sociedade.

A estrutura deste artigo compõe-se do referencial teórico: orçamento público, orçamento no GDF e créditos adicionais. Em seguida, apresentam-se a metodologia aplicada e o levantamento de dados Seção esta dividida em créditos adicionais no GDF de 2005 a 2008 e créditos adicionais por fonte de recurso e por unidades orçamentárias. Por último são feitas as considerações finais.

\section{ARCABOUÇO TEÓRICO}

\subsection{Orçamento público}

Com o advento da Revolução Industrial no Século XIX e ao longo do tempo, surgiu a necessidade de se implementarem mecanismos no sentido de proporcionar bases seguras na condução das atividades pretendidas. Tradicionalmente, o orçamento público era tratado como mera peça contábil-financeira que previa a receita e fixava a despesa sem preocupação com os planos governamentais. Em síntese, um documento de previsão de receita e autorização de despesa. O orçamento clássico ou tradicional, conforme sua classificação institucional, não priorizava as necessidades da coletividade e sua correção era baseada em gastos ocorridos no exercício anterior, ao invés de considerar ações que se pretendiam realizar futuramente. Tal definição tornou-se ultrapassada por não considerar programas de trabalho, além de não possuir a definição de objetivos. Com o tempo, o orçamento deixou de ter característica estática e passou a possuir aspecto dinâmico com vínculo no planejamento das ações de governo, chamado Orçamento-Programa, o qual foi introduzido no Brasil com a Lei $n^{\circ} 4.320 / 64$ e o Decreto-Lei $n^{\circ}$ 200/67, e reafirmado com a Lei Complementar $n^{\circ} 101 / 2000$. O orçamento deve ser visto como instrumento de planejamento da ação do governo, mediante a identificação dos seus programas, projetos e atividades, além do estabelecimento de objetivos e metas, bem como da previsão dos custos relacionados.

No Brasil, a elaboração orçamentária adota os seguintes procedimentos: inicia-se com um projeto de lei do orçamento elaborado pelo Poder Executivo, que será encaminhado ao Poder Legislativo para apreciação e aprovação. A Constituição Federal estabelece que cada Poder deve acompanhar e avaliar sua própria execução financeira, contábil, entre outras, tendo o Legislativo a competência de exercer o controle externo das coisas públicas.

Pode-se considerar o orçamento, quanto à sua natureza jurídica, como uma lei formal, ou seja, a simples fixação de despesa não cria vínculo à sua realização, sendo impossível exigir que uma despesa específica prevista no orçamento seja realizada. Por exemplo, o Poder Público pode deixar de realizar uma despesa autorizada pelo Legislativo, mas não pode realizar uma despesa não prevista.

Assim, o orçamento é uma lei formal, pois diversas vezes deixa de possuir a coercibilidade presente nas leis; é uma lei temporária, por possuir vigência limitada de um exercício; é uma lei ordinária por partir de um ato normativo primário contendo, em regra, normas gerais e abstratas - todas as leis orçamentárias (PPA, LDO e LOA) são leis ordinárias, bem como os créditos suplementares e especiais -; e uma lei especial, por possuir processo legislativo diferente e tratar de matéria específica.

O orçamento é utilizado como medida de aperfeiçoar a gestão pública. 
Consequentemente, seu correto planejamento é de imensurável importância à execução orçamentária, pois gera ganhos relevantes em razão da melhora na eficácia do processo decisório.

De acordo com Giacomoni (2005, p. 64),

O orçamento público caracteriza-se por possuir uma multiplicidade de aspectos: político, jurídico, contábil, econômico, financeiro, administrativo, dentre outros. Seu conceito tem sofrido significativas mudanças ao longo do tempo, em decorrência da evolução de suas funções, hoje marcadamente diversas daquelas que o distinguiam no passado. Assim, o entendimento de sua conceituação atual fica facilitado com base na análise que caracterizou a transformação de seus papéis principais, que, por sua vez, determinaram alterações na importância relativa de cada um dos aspectos citados.

Para Viana (1976, p. 26), “O orçamento é um instrumento de controle preventivo, assinalando o caminho a seguir pela administração e dando-lhe necessária autorização para arrecadar e gastar, dentro dos limites que se contêm no próprio orçamento”.

Considerando que o orçamento público tem origem no planejamento da gestão e toda a administração pública deve estabelecer os objetivos e metas a alcançar, aos gestores cabe pensar no que se fará durante o próximo exercício financeiro. Por meio desta análise, elaborase o orçamento. Mesmo assim, durante sua execução, percebe-se a necessidade de alterações mediante créditos adicionais no orçamento público. Isso faz cogitar: como executar o orçamento aprovado sem a necessidade de alterações orçamentárias? Seria possível e viável?

Em razão do fato de a receita orçamentária ser prevista e sua arrecadação não ser necessariamente o valor estimado inicialmente, pode haver a necessidade de modificar o orçamento. Tal alteração é concretizada por meio dos créditos adicionais com o intuito de suprir os gastos públicos.

\subsection{Orçamento no GDF}

A lei orçamentária anual - LOA estabelece os créditos de cada unidade orçamentária, sendo estes especificados por esfera, fonte de recursos, função, subfunção, programa, projeto, atividade, operações especiais, grupo de despesa e modalidade de aplicação. O Quadro de Detalhamento de Despesa - QDD - é um relatório detalhado que especifica o crédito orçamentário até o elemento de despesa.

Durante a execução orçamentária, é comum a necessidade de se abrir créditos adicionais. $\mathrm{O}$ órgão que necessita de tal retificação deve requerer a abertura do crédito para a Secretaria de Planejamento e Gestão - SEPLAG, o Órgão Central do Sistema de Planejamento e Orçamento do Governo do Distrito Federal. O requerimento deve conter a justificativa da necessidade e a respectiva origem do recurso compensatório, que pode ser oriundo de: (i) superávit financeiro (ii) excesso de arrecadação (iii) anulação parcial ou total de dotação orçamentária ou de créditos adicionais; e (iv) provenientes de operações de crédito, convênios e outros ajustes firmados com entidades públicas ou particulares.

\subsection{Créditos adicionais}

Conforme a Lei $n^{\circ}$ 4.320/64, em seu artigo 40, "são créditos adicionais as autorizações de despesa não computadas insuficientemente dotadas na Lei de Orçamento”. Os créditos adicionais classificam-se em:

$\Rightarrow$ Créditos Suplementares: que se destinam ao reforço, complemento da dotação orçamentária já existente. 
$\Rightarrow$ Créditos Especiais: utilizados para despesas sem dotação específica. Despesas novas, não autorizadas na lei orçamentária.

$\Rightarrow$ Créditos Extraordinários: destinados a atender despesas imprevisíveis e urgentes, como as decorrentes de guerra, comoção interna e nos casos de calamidade pública.

O Quadro 1 apresenta as principais características dos créditos adicionais de acordo com a Constituição Federal e a Lei nº 4.320/64.

\begin{tabular}{|c|c|c|c|}
\hline Espécie & Suplementares & Especiais & Extraordinários \\
\hline Finalidade & $\begin{array}{l}\text { Reforço da categoria } \\
\text { de programação na LOA }\end{array}$ & $\begin{array}{l}\text { Atender à categoria } \\
\text { de programação } \\
\text { não contemplada } \\
\text { no orçamento }\end{array}$ & $\begin{array}{l}\text { Atender a despesas } \\
\text { imprevisíveis e urgentes }\end{array}$ \\
\hline Autorização & $\begin{array}{l}\text { Prévia, podendo ser incluída } \\
\text { na própria lei de orçamento } \\
\text { ou em lei especial }\end{array}$ & Prévia, em lei especial & Independente \\
\hline \multirow[t]{2}{*}{ Forma de Abertura } & \multirow{2}{*}{$\begin{array}{l}\text { União: Decreto do Pres. da } \\
\text { República até o limite em lei } \\
\text { GDF: Decreto do Gov. até o } \\
\text { limite estabelecido em lei }\end{array}$} & \multirow{2}{*}{$\begin{array}{l}\text { União: Decreto do Pres. } \\
\text { da República até o limite } \\
\text { em lei } \\
\text { GDF: Decreto do Gov. } \\
\text { até o limite estabelecido } \\
\text { em lei }\end{array}$} & $\begin{array}{l}\text { União: por meio de } \\
\text { Medida Provisória. }\end{array}$ \\
\hline & & & $\begin{array}{l}\text { Nos Estados } \\
\text { Municípios: Decreto } \\
\text { GDF: Decreto }\end{array}$ \\
\hline Recursos & Indicação obrigatória & Indicação obrigatória & $\begin{array}{ll}\text { Independente } & \text { de } \\
\text { indicação } & \end{array}$ \\
\hline Valor/Limite & $\begin{array}{l}\text { Obrigatório, indicado na lei } \\
\text { de autorização e no decreto } \\
\text { de abertura }\end{array}$ & $\begin{array}{l}\text { Obrigatório, indicado na } \\
\text { lei de autorização e no } \\
\text { decreto de abertura }\end{array}$ & $\begin{array}{l}\text { Obrigatório } \\
\text { União: indicado por meio } \\
\text { de Medida Provisória. } \\
\text { GDF: Decreto }\end{array}$ \\
\hline Vigência & $\begin{array}{l}\text { No exercício em que foi } \\
\text { aberto }\end{array}$ & $\begin{array}{l}\text { No exercício em que foi } \\
\text { aberto }\end{array}$ & $\begin{array}{l}\text { No exercício em que foi } \\
\text { aberto }\end{array}$ \\
\hline Prorrogação & Jamais permitida & \begin{tabular}{lcr} 
Só para & o & exercício \\
seguinte, se & autorizada \\
em um & dos & quatro \\
últimos & meses & do \\
exercício. & \multicolumn{2}{c}{}
\end{tabular} & $\begin{array}{lcr}\text { Só para } & \text { o } & \text { exercício } \\
\text { seguinte, se } & \text { autorizada } \\
\text { em um } & \text { dos } & \text { quatro } \\
\text { últimos } & \text { meses } & \text { do } \\
\text { exercício. } & & \end{array}$ \\
\hline
\end{tabular}

Quadro 1. Principais características das modalidades de créditos adicionais

Fonte: LIMA; CASTRO (2007, p. 27) com adaptações.

Os créditos extraordinários, de acordo com a Lei $\mathrm{n}^{0}$ 4.320/64, serão abertos por Decreto do Poder Executivo, que dará conhecimento imediato ao Legislativo. Para a União, vale o que dispõe a Constituição em seu artigo 167, § $3^{\circ}$, ou seja, os créditos extraordinários serão abertos por medida provisória.

Conforme o art. 43 da Lei ${ }^{\circ} 4.320$ :

A abertura dos créditos suplementares e especiais depende da existência de recursos disponíveis para ocorrer a despesa e será precedida de exposição justificativa.

$\S 1^{\circ}$ Consideram-se recursos para o fim deste artigo, desde que não comprometidos: 
I - o superávit financeiro apurado em balanço patrimonial do exercício anterior;

II - os provenientes de excesso de arrecadação;

III - os resultantes de anulação parcial ou total de dotações orçamentárias ou de créditos adicionais, autorizados em Lei;

IV - o produto de operações de crédito autorizadas, em forma que juridicamente possibilite ao Poder Executivo realizá-las.

$\S 2^{\circ}$ Entende-se por superávit financeiro a diferença positiva entre o ativo financeiro e o passivo financeiro, conjugando-se, ainda, os saldos dos créditos adicionais transferidos e as operações de crédito a eles vinculadas.

$\S 3^{\circ}$ Entende-se por excesso de arrecadação, para os fins deste artigo, o saldo positivo das diferenças acumuladas mês a mês entre a arrecadação prevista e a realizada, considerando-se, ainda, a tendência do exercício.

$\S 4^{\circ}$ Para o fim de apurar os recursos utilizáveis, provenientes de excesso de arrecadação, deduzir-se-á a importância dos créditos extraordinários abertos no exercício.

A Lei no 4.320 expressa, no artigo 46, que "o ato que abrir crédito adicional indicará a importância, a espécie do mesmo e a classificação da despesa, até onde for possível”.

\section{METODOLOGIA}

Para a realização deste trabalho, utilizou-se das pesquisas bibliográfica e documental. A primeira com o auxílio de obras (livros, artigos e sites), enquanto a segunda foi realizada com documentos de órgãos do GDF.

Os dados foram obtidos junto ao Sistema de Integração de Gestão Governamental SIGGO, responsável pela condução das diversas etapas do processo orçamentário do GDF. O SIGGO corresponde ao SIAFI - Sistema Integrado de Administração Financeira do Governo Federal -, utilizado pela União. O SIGGO foi implantado em 2000, substituindo o SIAFEN Sistema Integrado de Administração Financeira para Estados e Municípios -.

\section{RESULTADOS E ANÁLISE}

\subsection{Créditos adicionais do período 2005 a 2008}

As leis orçamentárias anuais do período considerado nesta pesquisa formam as seguintes:

$\Rightarrow$ 2005: Lei $\mathrm{n}^{\circ}$ 3.519, de 30 de dezembro de 2004;

$\Rightarrow$ 2006: Lei ${ }^{\circ} 3.766$, de 27 de janeiro de 2006;

$\Rightarrow$ 2007: Lei ${ }^{\circ}$ 3.934, de 29 de dezembro de 2006;

$\Rightarrow$ 2008: Lei ${ }^{\circ} 4.073$, de 28 de dezembro de 2007.

Há de comum nessas leis, conforme o título IV que trata das disposições finais, no artigo $8^{\circ}$, inciso I, que os créditos suplementares autorizados na própria lei orçamentária serão abertos visando ao atendimento às insuficiências orçamentárias, não podendo ultrapassar o limite de vinte e cinco por cento do valor total de cada unidade orçamentária. A Lei $\mathrm{n}^{\circ}$ 3.766, referente ao exercício de 2006, diferencia-se, dispondo que o limite deve ser de vinte e cinco por cento do valor de cada atividade ou projeto autorizado. 
Os dados apresentados na Tabela 1 e ilustrados no Gráfico 1, foram coletados do SIGGO e referem-se aos créditos adicionais abertos no período entre 2005 a 2008, destacados por modalidades: suplementares, especiais e extraordinários:

Tabela 1 - Orçamento do GDF - Créditos adicionais abertos no período 2005-2008

Em R\$ 1.000,00

\begin{tabular}{l|c|c|c|c}
\hline & $\mathbf{2 0 0 5}$ & $\mathbf{2 0 0 6}$ & $\mathbf{2 0 0 7}$ & $\mathbf{2 0 0 8}$ \\
\hline Suplementares & 2.885 .151 & 3.706 .619 & 3.249 .991 & 4.430 .789 \\
Especiais & 66.929 & 98.798 & 355.465 & 272.098 \\
Extraordinários & - & - & - & - \\
\hline TOTAL & $\mathbf{2 . 9 5 2 . 0 8 1}$ & $\mathbf{3 . 8 0 5 . 4 1 7}$ & $\mathbf{3 . 6 0 5 . 4 5 7}$ & $\mathbf{4 . 7 0 2 . 8 8 8}$ \\
\hline
\end{tabular}

Fonte: elaboração própria a partir do SIGGO.

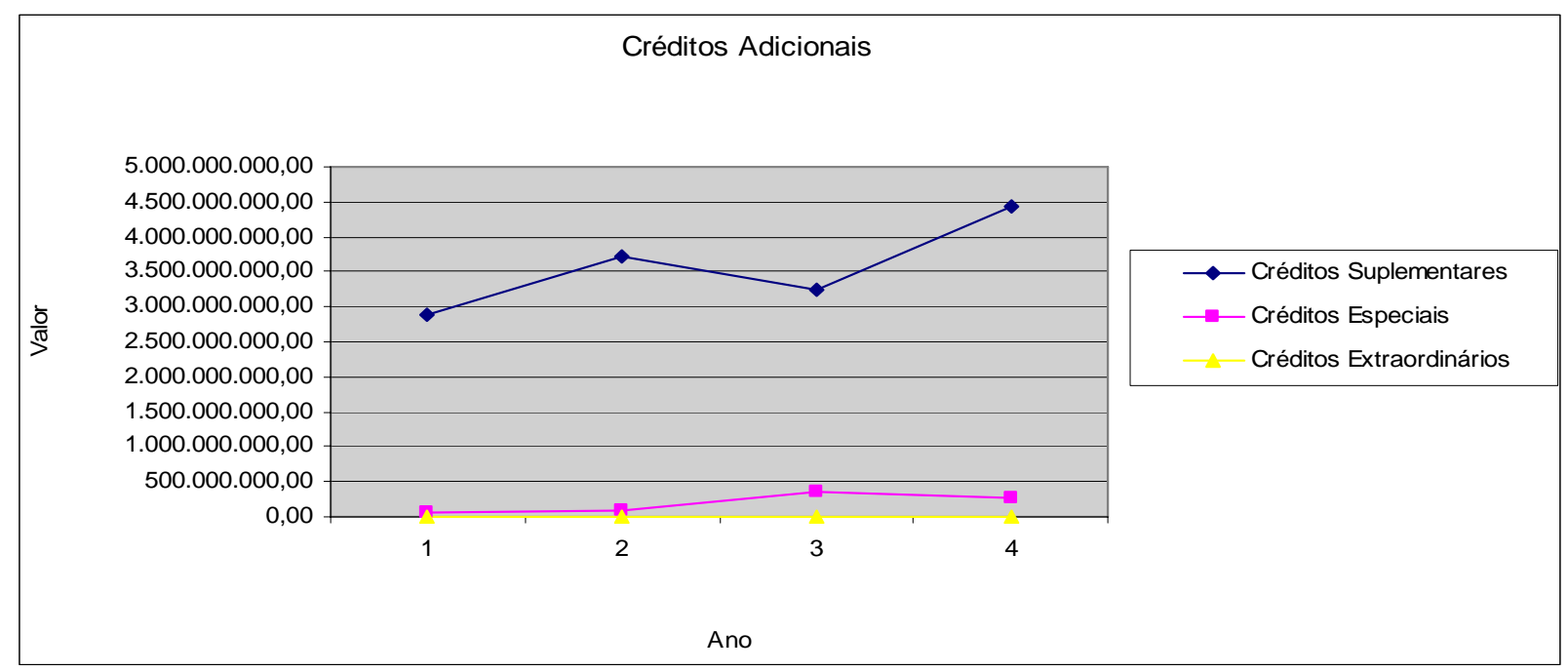

Gráfico 1 - Orçamento do GDF - Créditos Adicionais abertos no período 2005-2008

Fonte: elaboração própria a partir do SIGGO.

Não houve no período crédito extraordinário, já que inexistiram situações imprevisíveis e urgentes no DF que justificassem a abertura desse tipo de crédito.

Os dados demonstram tendência de crescimento tanto dos créditos suplementares como dos especiais. Os créditos suplementares, como era de esperar, alcançam montante bem superior aos especiais. Ocorreu pequena queda em relação ao ano anterior no montante de créditos suplementares abertos em 2007, e nos créditos especiais abertos em 2008.

A Tabela 2 demonstra o montante das dotações iniciais abertas em cada exercício analisado, bem como o total dos respectivos créditos abertos para cada ano. Os percentuais de comparação entre os dois dados a cada exercício possibilitam concluir como são elevados os montantes de alterações orçamentárias praticadas no âmbito do GDF.

Tabela 2 - Orçamento do GDF - Dotação inicial e créditos adicionais abertos no período 2005-2008

\begin{tabular}{c|c|c|c}
\multicolumn{5}{|c}{ Em R\$ $1.000,00$} \\
\hline ANO & DOTAÇÃO INICIAL & CRÉDITOS ADICIONAIS & \% \\
2005 & 7.723 .178 & 2.952 .081 & 38,22 \\
2006 & 8.169 .879 & 3.805 .417 & 46,58 \\
2008 & 9.898 .039 & 3.605 .457 & 36,42 \\
\end{tabular}

Fonte: elaboração própria a partir do SIGGO.

Em dois exercícios do período considerado - 2006 e 2008 -, o montante de créditos 
adicionais alcançou valores próximos a 50\% do orçamento inicial. Esse expressivo valor chama muito a atenção, pois significa que quase a metade do orçamento inicial acaba sendo alterado durante a execução.

\subsection{Créditos adicionais por fonte de recurso}

Na Tabela 3, observa-se o montante total de créditos adicionais abertos e a origem dos recursos compensatórios, a saber: (i) por excesso da arrecadação; (ii) convênios; (iii) operações de crédito; (iv) anulação total ou parcial de dotações orçamentárias; (v) superávit financeiro.

Tabela 3 - Orçamento do GDF - Créditos adicionais abertos no período 2005-2008 segundo as fontes de recursos

\begin{tabular}{c|c|c|c|c|c|c}
\hline ANO & Exc. Arrecad. & Exc. Convênio & Op. de Crédito & Anulação & Superávit & TOTAL \\
\hline 2005 & 271.151 & 76.625 & 131.880 & 2.379 .776 & 92.646 & 2.952 .081 \\
2006 & 695.437 & 167.937 & 178.874 & 2.633 .191 & 129.975 & 3.805 .417 \\
2007 & 128.853 & 73.596 & 6.923 & 3.255 .445 & 140.637 & 3.605 .457 \\
2008 & 1.037 .567 & 290.102 & 206.041 & 2.626 .490 & 542.685 & 4.702 .888 \\
\hline
\end{tabular}

Fonte: elaboração própria a partir do SIGGO.

A respeito dos créditos adicionais abertos por excesso de arrecadação, pode-se afirmar que são créditos abertos com base na constatação de arrecadação financeira acima do previsto para o exercício. Os por convênio ocorrem quando dois ou mais órgãos se juntam em prol de um benefício comum. Quando isso ocorre, o GDF disponibiliza recursos para que o projeto seja realizado. As operações de crédito são novos empréstimos e também podem ser utilizadas para abertura de créditos adicionais. Os créditos abertos por anulação total ou parcial se originam do cancelamento do recurso autorizado na dotação inicial. Para que o saldo da anulação possa ser usado, abre-se crédito adicional por anulação. Por fim, há os créditos abertos com base no superávit financeiro apurado em Balanço Patrimonial do exercício anterior, caracterizando-se por ser a diferença positiva entre o ativo financeiro e o passivo financeiro.

Durante o período analisado, os créditos adicionais abertos por excesso de arrecadação foram os mais inconstantes, duplicando-se em 2006 em relação a 2005, logo após decaindo mais de cinco vezes. Em compensação, em 2008, o montante aumentou mais de seis vezes. Os créditos que se originaram dos convênios duplicaram seu valor em 2006, caindo na mesma proporção em 2007, e, em 2008, seu valor triplicou. Os créditos adicionais advindos de operações de crédito mantiveram valores próximos em 2005 a 2006, decaindo muito em 2007, retornando, em 2008, à mesma média registrada em 2005.

Observa-se que o montante mais representativo é o dos créditos originados por anulações totais ou parciais, que representaram, em todos os anos, mais da metade da abertura dos créditos. Em 2007, chegou a 90,29\% do montante total e, em 2008, registrou seu mínimo de 55,85\%. Mesmo assim, esse mínimo é significativo, já que representa mais da metade do valor total. É discutível a utilização intensiva desse tipo de mecanismo, pois anulam-se créditos autorizados em lei transformando-os em outros créditos, em boa parte por meio de decreto do Poder Executivo, isto é, sem a manifestação do Poder Legislativo. Os créditos adicionais abertos com base no superávit financeiro mantiveram-se constantes de 2005 a 2007, chegando a triplicar seu valor em 2008.

A dotação orçamentária inicial disponibilizada ao GDF, somada com o total de 
créditos adicionais deduzidos os créditos abertos por anulações realizados durante o exercício, totaliza o montante das dotações autorizadas ao final do exercício. Na Tabela 4, tem-se o total dos créditos adicionais líquidos, deduzidas as anulações.

Tabela 4 - Orçamento do GDF - Créditos adicionais abertos no período 2005-2008 segundo as fonte de recursos

\begin{tabular}{c|c|c|c|c|c|c}
\hline ANO & $\begin{array}{c}\text { Excesso de } \\
\text { Arrecadação }\end{array}$ & Exc. Convênio & $\begin{array}{c}\text { Op. de } \\
\text { Crédito }\end{array}$ & Anulação & Superávit & $\begin{array}{c}\text { Créd. Adic. } \\
\text { líquido }\end{array}$ \\
\hline 2005 & 271.151 & 76.625 & 131.880 & 2.379 .776 & 92.646 & 572.304 \\
2006 & 695.437 & 167.937 & 178.874 & 2.633 .091 & 129.975 & 1.172 .225 \\
2007 & 128.853 & 73.596 & 6.923 & 3.255 .445 & 140.637 & 350.011 \\
2008 & 1.037 .567 & 290.102 & 206.041 & 2.626 .490 & 542.685 & 2.076 .397 \\
\hline
\end{tabular}

Fonte: elaboração própria a partir do SIGGO.

A última coluna da Tabela 4 representa o valor dos respectivos créditos adicionais líquidos da anulação. Seu cálculo deu-se pela soma de todas as origens apresentadas acima, deduzindo-se o valor das anulações para que não haja a dupla contagem. Quando um crédito adicional é aberto por anulação esse valor não aumenta a dotação final autorizada, pois o mesmo já foi autorizado no montante da dotação inicial.

Matematicamente, essa dedução dos créditos adicionais não tem muita importância. Mas orçamentariamente faz toda a diferença, pois, se um valor foi anulado para ser reaberto por meio dos créditos adicionais, significa que seu recurso não vai ser gasto na respectiva despesa autorizada no orçamento inicial. Dessa forma, o planejado inicialmente não será realizado.

\subsection{Créditos adicionais por unidade orçamentária}

A seguir, a Tabela 5 discrimina os créditos adicionais abertos no período entre 2005 a 2008 em cada unidade orçamentária do Governo do Distrito Federal.

Tabela 5 - Orçamento do GDF - Créditos adicionais abertos no período 2005-2008 por unidade orçamentária

\begin{tabular}{l|l|r|r|r|r}
\multicolumn{1}{|c}{ UNIDADE ORÇAMENTÁRIA } & $\mathbf{2 0 0 5}$ & $\mathbf{2 0 0 6}$ & $\mathbf{2 0 0 7}$ & $\mathbf{2 0 0 8}$ \\
\hline UO & Em R\$1.000,00 \\
\hline 01101 & Câmara Legislativa do DF & 26.598 & 21.542 & 40.643 & 18.697 \\
02101 & Tribunal de Contas do Distrito Federal & 6.501 & 8.440 & 14.999 & 34.222 \\
10101 & Gabinete do Vice-Governador & 666 & 377 & 775 & 870 \\
11101 & Secretaria de Estado do Governo & 142.824 & 87.735 & 279.322 & 252.632 \\
12101 & Procuradoria Geral do Distrito Federal & 29.624 & 14.715 & 12.937 & 29.666 \\
13101 & Secret. de Estado de Gestão Administrativa & 158.281 & 154.151 & - & - \\
14101 & Secret. de Est.de Agric. Pec. e Abastecimento & 18.960 & 55.737 & 39.835 & 34.859 \\
15101 & Secret. De Estado de Comunicação Social & 865 & 1.936 & - & - \\
16101 & Secretaria de Estado de Cultura & 10.755 & 22.533 & 22.562 & 36.104 \\
17101 & Secret. de Estado de Desenvolv. Social & 83.807 & 70.222 & 165.021 & 132.772 \\
18101 & Secretaria de Estado de Educação & 318.711 & 484.735 & 451.760 & 1.101 .008 \\
19101 & Secretaria de Estado de Fazenda & 137.592 & 246.208 & 212.121 & 532.444 \\
20101 & Secret. de Est. Desenv. Econômico de Turismo & 1.053 & 933 & 40.979 & 41.182 \\
21101 & Secret. de Meio Ambiente e Recursos Hídricos & 39.271 & 42.966 & - & - \\
22101 & Secretaria de Estado de Obras & 824.825 & 1.258 .696 & 349.826 & 637.163 \\
23101 & Fundação Hemocentro de Brasília & 521.145 & 555.509 & 654.461 & 536.245 \\
24101 & Secretaria de Estado de Segurança Pública & 112.538 & 98.807 & 80.360 & 117.165
\end{tabular}




\begin{tabular}{l|l|r|r|r|r}
25101 & Secretaria de Estado de Trabalho & 35.674 & 66.266 & - & 28.510 \\
26101 & Secretaria de Estado de Transportes & 10.019 & 8.245 & 280.359 & 397.330 \\
27101 & Secretaria de Estado de Turismo & 3.276 & 2.689 & - & - \\
28101 & Secret. de Estado de Desenv. Urbano e Meio Ambiente & 27.669 & 22.843 & 556.216 & 336.754 \\
32101 & Secret. de Estado de Planej. e Gestão & 241.155 & 336.207 & 232.238 & 232.606 \\
33101 & Secretaria de Estado de Solidariedade & 10.232 & 19.873 & - & - \\
34101 & Secretaria de Estado de Esporte & 10.558 & 9.185 & 13.289 & 40.702 \\
36101 & Secret. de Estado de Articulação p/ Desenv. do Entorno & 1.396 & 2.377 & - & - \\
38101 & Secret. de Estado de Coordenação das Administrações & 145.991 & 180.710 & - & - \\
40101 & Secret. de Estado de Ciência e Tecnologia & 15.446 & 13.734 & 22.344 & 35.942 \\
41101 & Secret. de Estado de Fiscalização de Atividades & - & 1.060 & - & - \\
42101 & Secretaria de Estado de Assuntos Sindicais & 440 & - & - & - \\
43101 & Secretaria de Estado de Administr. de Parques & 16.205 & 16.973 & - & - \\
44101 & Secret. de Estado de Justiça, Direitos Humanos & - & - & 120.797 & 91.112 \\
45101 & Corregedoria Geral do Distrito Federal & - & - & 14.602 & 7.556 \\
47101 & Secretaria de Estado de Habitação do DF & - & - & - & 27.334 \\
\hline TOTAL & & $\mathbf{2 . 9 5 2 . 0 9 1}$ & $\mathbf{3 . 8 0 5 . 4 1 7}$ & $\mathbf{3 . 6 0 5 . 4 5 7}$ & $\mathbf{4 . 7 0 2 . 8 8 8}$ \\
\hline
\end{tabular}

Fonte: elaboração própria a partir do SIGGO.

No período referido, a abertura de créditos concentra-se nas áreas de Obra e Educação, atingindo, respectivamente, $\mathrm{R}$ \$ 3.070.512.328,13 e R\$ 2.356.215.468,00. Assim, os recursos inicialmente dotados para a Sec. de Estado de Obras e Sec. de Estado de Educação não foram suficientes à demanda, sendo necessário complementar com a abertura de créditos adicionais.

Abaixo duas tabelas, detalhando a situação das Secretarias de Estado destacadas.

Tabela 6 - Orçamento da Secretaria de Obras do GDF Dotação inicial, créditos adicionais totais e por anulação no período 2005-2008

\begin{tabular}{c|c|c|c|c}
\multicolumn{2}{|c}{} & \multicolumn{2}{c}{ Em R\$1,00 } \\
\hline Ano & Dotação Inicial & Créd. Adicionais & Por Anulação & \% \\
\hline 2005 & $1.300 .574 .193,00$ & $824.825 .210,00$ & $593.476 .221,00$ & 63,42 \\
2006 & $1.506 .427 .563,00$ & $1.258 .696 .871,00$ & $718.978 .060,00$ & 83,55 \\
2007 & $1.924 .899 .862,00$ & $349.826 .775,13$ & $302.454 .258,00$ & 18,17 \\
2008 & $816.410 .010,00$ & $637.163 .472,00$ & $242.738 .747,00$ & 78,04 \\
\hline TOTAL & $\mathbf{5 . 5 4 8 . 3 1 1 . 6 2 8 , 0 0}$ & $\mathbf{3 . 0 7 0 . 5 1 2 . 3 2 8 , 1 3}$ & $\mathbf{1 . 8 5 7 . 6 4 7 . 2 8 6 , 0 0}$ & \\
\hline
\end{tabular}

Fonte: elaboração própria a partir do SIGGO.

Partindo do princípio de que os créditos adicionais auxiliam na execução orçamentária, acrescentando ao orçamento uma dotação até então não existente, pode-se afirmar que, na Secretaria de Estado de Obras, houve grande alteração, visto que os créditos adicionais foram bastante representativos em relação à dotação inicial. Essas alterações sugerem que, ao final do exercício, a execução do orçamento não ocorreu conforme o aprovado inicialmente, permitindo supor que as metas fixadas não tenham sido cumpridas, perdendo-se a eficácia do planejamento. Ainda na área de Obras, em 2006, os créditos adicionais totais chegaram a representar $83,55 \%$ da dotação inicial. Na tabela, o valor dos créditos adicionais demonstrado é o valor bruto, incluindo as anulações. Observa-se pela coluna dos créditos abertos somente por anulação que seu valor representa mais da metade do montante total dos créditos adicionais. 


\section{Tabela 7 - Orçamento da Secretaria de Estado de Educação do GDF Dotação inicial, créditos adicionais totais e por anulação no período} 2005-2008

\begin{tabular}{ccccc}
\hline & & \multicolumn{2}{c}{ Em R $\$ 1,00$} \\
\hline Ano & Dotação Inicial & Créd. Adicionais & Por Anulação & \% \\
\hline 2005 & $1.102 .497 .818,00$ & $318.711 .161,00$ & $273.271 .482,00$ & 50,57 \\
2006 & $958.475 .856,00$ & $484.735 .293,00$ & $305.909 .976,00$ & 39,82 \\
2007 & $1.134 .427 .641,00$ & $451.760 .989,00$ & $423.125 .540,00$ & 39,69 \\
TOTAL & $\mathbf{4 . 7 0 1 . 9 9 7 . 4 6 5 , 0 0}$ & $\mathbf{2 . 3 5 6 . 2 1 5 . 4 6 8 , 0 0}$ & $\mathbf{1 . 9 5 6 . 7 7 1 . 0 5 5 , 0 0}$ & \\
\hline
\end{tabular}

Fonte: elaboração própria a partir do SIGGO.

Com a Secretaria de Estado de Educação, não foi diferente. Os valores dos créditos adicionais também representam grande parcela da dotação inicial e entre os créditos abertos a maior parte é de créditos abertos por anulação total ou parcial. Em 2008, os créditos abertos atingiram 73,08\% do aprovado inicialmente. Esse excesso de abertura de créditos, em princípio compromete a correta gestão, não sendo possível executar o planejado inicialmente.

\section{CONSIDERAÇÕES FINAIS}

Este artigo buscou analisar os créditos adicionais abertos de 2005 a 2008 no GDF, identificar as fontes que possibilitaram a abertura dos respectivos créditos e observar como esses recursos são utilizados pelo referido governo nos últimos anos.

Os créditos suplementares são mais usados que os créditos especiais, já que o primeiro tem a finalidade de reforçar dotações, enquanto o segundo é aberto para a criação de novas despesas. Não foi aberto crédito extraordinário no DF, durante o período relacionado neste trabalho. Das origens dos créditos adicionais, nota-se que a maior incidência advém dos abertos por anulação total ou parcial, em segundo lugar, por excesso de arrecadação e em terceiro, os derivados de superávit financeiro. As aberturas realizadas por convênio e operações de crédito são as menos utilizadas, conforme os dados coletados.

Os créditos adicionais são medidas que auxiliam na execução orçamentária, mas há um abuso no emprego desse recurso. O montante de créditos adicionais abertos é tanto que chega a representar quase a metade da dotação inicial. Assim, o orçamento sofre significativas alterações durante o exercício. Talvez um aperfeiçoamento na fiscalização, a fim de inspecionar se os gastos estão ocorrendo de forma plausível, possa ajudar na redução de despesas desnecessárias, não sendo necessária a abertura demasiada de créditos adicionais.

Para novas investigações, é interessante o aprofundamento nos créditos adicionais por unidades orçamentárias, podendo também especificar o motivo das anulações ocorridas, bem como o porquê da abertura de cada crédito, pois este artigo limitou-se a explorar os montantes totais, sem a especificação dos motivos de cada anulação total ou parcial, por exemplo.

Entendeu-se que por mais que haja um planejamento a respeito da execução orçamentária prevista para determinado exercício financeiro, ao longo da execução do orçamento, há muitas mudanças, não sendo executado plenamente o que foi previsto. Essa flexibilidade é boa em relação aos ajustes necessários, já que é impossível executar exatamente o programado. Por outro lado, essas "brechas" orçamentárias, quando usadas de forma exacerbada, dificultam a correta realização das ações governamentais. 


\section{REFERÊNCIAS}

BRASIL. Constituição da República Federativa do Brasil. Brasília: Senado Federal, 1988.

Lei 4.320, de 17 de março de 1964. Estatui Normas Gerais de Direito Financeiro para elaboração e controle dos orçamentos e balanços da União, dos Estados, dos Municípios e do Distrito Federal. Brasília: 1964. Disponível em: <http://www.planalto.gov.br>. Acesso em: 11 de setembro de 2009.

Lei 3.519, de 30 de dezembro de 2004. Estima a Receita e fixa a Despesa do Distrito Federal para o exercício de 2005. Disponível em: <http://www.seplag.df.gov.br>. Acesso em: 08 de novembro de 2009.

Lei 3.766, de 27 de janeiro de 2006. Estima a Receita e fixa a Despesa do Distrito Federal para o exercício de 2006. Disponível em: <http://www.seplag.df.gov.br $>$. Acesso em: 08 de novembro de 2009.

Lei 3.934, de 29 de dezembro de 2006. Estima a Receita e fixa a Despesa do Distrito Federal para o exercício de 2007. Disponível em: <http://www.seplag.df.gov.br>. Acesso em: 08 de novembro de 2009.

Lei 4.073, de 28 de dezembro de 2007. Estima a Receita e fixa a Despesa do Distrito Federal para o exercício de 2008. Disponível em: <http://www.seplag.df.gov.br>. Acesso em: 08 de novembro de 2009.

CARVALHO, Deusvaldo. Orçamento e contabilidade pública: teoria, prática. São Paulo: Ática, 2005.

GIACOMONI, James. Orçamento público. 13. ed. São Paulo: Atlas, 2005.

LIMA, Diana Vaz de; CASTRO, Robison Gonçalves de. Contabilidade pública: integração União, Estados e Municípios (Siafi e Siafem). 3. ed. São Paulo: Atlas, 2007.

MOTA, Francisco Glauber Lima. Curso básico de contabilidade pública. 1. ed. Brasília: Brasiliense, 2005.

PISCITELLI, Roberto Bocaccio; TIMBÓ, Maria Zulene Farias; ROSA, Maria Berenice. Contabilidade pública: uma abordagem da Administração Financeira Pública. 7. ed. São Paulo: Atlas, 2002.

VIANA, Cibilis da Rocha. Compêndio de contabilidade geral. 6. ed. Porto Alegre: Sulina, 1976. 